\title{
La solución técnica a los problemas ambientales
}

\author{
Guillermo Foladori \\ Universidad Autónoma de Zacatecas (UAZ), México
}

\author{
Humberto Tommasino \\ Universidad de la República (Udelar), Uruguay
}

\section{La solución técnica a los problemas ambientales}

Resumen: En este ensayo se argumenta que la discusión ambiental ha sido reducida a una cuestión técnica. Y que esta supuesta reducción implica considerar a la tecnología como neutra y no incorporar las tendencias derivadas de las relaciones sociales. Se concluye con los límites que las relaciones capitalistas implican para solucionar los grandes problemas ambientales.

Palabras claves: Medio ambiente. Sustentabilidad. Naturaleza.

\section{A solução técnica para os problemas ambientais}

Resumo: Neste ensaio, argumenta-se que a discussão ambiental tem sido reduzida a uma questão técnica. E que esta dita redução implica em considerar a tecnologia como neutra e não em considerar as tendências derivadas das relações sociais. Conclui-se com os limites que as relações capitalistas supõem para solucionar os grandes problemas ambientais.

Palavras chave: Meio ambiente. Sustentabilidade. Natureza.

\section{The Technical Solution to Environmental Problems}

Abstract: This essay argues that the environmental discussion has been reduced to a technical question. This implies envisioning technology as neutral and does not consider social relations. It concludes by indicating limits to resolving the great environmental problems implied by capitalist relations.

Keywords: Environment. Sustainability. Nature. 


\section{De cómo un problema social se transformó en técnico}

La moderna conciencia ambiental es de los años sesenta del siglo 20. Pero fue en torno al concepto de desarrollo sustentable, bautizado en el documento Nuestro Futuro Común, que se incorporó en las agendas políticas el tema ambiental dentro de los planes de desarrollo. Como resultado natural de la confrontación de ideas, y no de forma planeada, se llegó a un acuerdo tácito de cómo debía entenderse la relación entre naturaleza y sociedad. Este acuerdo tácito se basa en considerar a la naturaleza como externa al ser humano y, como resultado, asumir que lo único que afecta a la naturaleza es la tecnología. Veamos esto con mayor detalle.

La pregunta ¿qué se considera naturaleza o ambiente? es el punto de partida para entender toda la discusión ambiental. Hay dos grandes respuestas. Una es considerar el medio ambiente o naturaleza como lo externo al ser humano. Naturaleza externa al ser humano es todo lo que no es humano. Esta es la forma corriente en que se entiende a la naturaleza. Con esto no se niega el carácter natural del ser humano; simplemente se distingue lo humano de lo no humano, y se restringe el término naturaleza a lo segundo. Otra respuesta es incluir al ser humano y sus relaciones en el concepto de naturaleza. Estas dos respuestas permean la discusión sobre sustentabilidad y las políticas ambientales.

Ahora bien, si se toma la primera respuesta, el considerar la naturaleza como lo externo al ser humano, entonces los problemas de desarrollo, de desigualdad, de pobreza, etc., quedan fuera de la discusión ambiental. Surge, entonces, un problema práctico, porque lo ambiental no encaja dentro de las políticas de desarrollo que son sociales; o bien encaja forzadamente, es decir poniendo límites a determinadas políticas, como es el caso de los instrumentos económicos que castigan la contaminación y degradación o incentivan la producción limpia o verde. Pero desde este punto de vista lo ambiental siempre es marginal a las políticas económicas y sociales.

Si se toma la segunda respuesta, que consiste en considerar a lo humano como parte de la naturaleza, entonces no hay distinción entre lo que es naturaleza externa y lo que es naturaleza interna. En este caso lo ambiental se desvanece, porque no hay manera de darle especificidad.

La evolución de la confrontación de ideas permitió llegar a una solución intermedia, tácita, pero que se ha convertido en hegemónica y es aplicada en las políticas de desarrollo. Esta solución significó reunir los dos criterios (naturaleza como lo externo y naturaleza incluyendo al ser humano) en una sola. ¿Pero, cómo llegar a una solución que tome los dos criterios sin diluir el problema?
La solución, que de hecho es la posición mayoritaria de instituciones y gobiernos, y que se conoce como "ambientalismo moderado", fue ampliar el primer criterio (naturaleza como lo externo al ser humano) incorporándole los problemas sociales que resultan en depredación y/o contaminación.

Un ejemplo simple es la pobreza. La pobreza en sí misma no es un problema ambiental, es un problema social. Sin embargo, constituye un problema ambiental el hecho de que los pobres degraden o contaminen la naturaleza externa.

Otro ejemplo simple es la riqueza. La riqueza no es un problema ambiental, lo que constituye un problema es que los ricos degraden (consuman demasiado) o contaminen (usen tecnologías contaminantes). ${ }^{1}$

Entonces la solución ha sido considerar que los problemas sociales (naturaleza humana) no son el objetivo de la política ambiental, pero pueden ser el puente para llegar al objetivo final que es la naturaleza externa. Combatir la pobreza tiene sentido, desde una perspectiva ambiental, si es un medio o puente para evitar la degradación y/o contaminación del ambiente externo.

Dicho de otra forma: si los pobres no contaminaran o degradaran no habría problema ambiental. Si los ricos no consumieran de más, o no contaminaran no habría problema ambiental.

Pero, esta solución, aparentemente elegante, implicó reducir toda la problemática ambiental a cuestiones técnicas y ocultar el efecto de las relaciones sociales sobre la naturaleza externa. Y esto porque la forma que tiene el ser humano de transformar la naturaleza externa es mediante su tecnología. Relaciones técnicas son las que establece el ser humano con su ambiente externo.

\section{De cómo la solución técnica permitió organizar y clasificar la problemática ambiental}

Supongamos un agricultor que produce trigo utilizando tractores y agrotóxicos. Establece una determinada relación técnica con la naturaleza externa, diferente a la que podría establecer si trabajara con tracción animal y con abono. La tecnología difiere en uno y otro caso, si entendemos por tecnología los conocimientos e instrumentos necesarios para transformar la naturaleza - el suelo en este ejemplo. Pero sea cual fuere la relación técnica, eso poco nos dice, o sólo indirectamente nos da pistas de cuál es la relación social que está por detrás. No sabemos si se trata de un productor independiente, de un obrero asalariado, de un miembro de una cooperativa; tampoco sabemos si es dueño del suelo o arrendatario; y menos sabemos si solicitó crédito, o quienes serán los consumidores de su producto. Todas estas son 
relaciones sociales, que las relaciones técnicas no necesariamente revelan. Aunque relaciones sociales y relaciones técnicas se dan simultánea e interconectadamente, ambas pueden y deben ser distinguidas con fines analíticos.

Cuando se presta atención al impacto de la actividad humana sobre el ambiente externo se está enfocando el análisis a las relaciones técnicas. Lo "humano" sólo se analiza como una relación técnica con la naturaleza, por lo tanto la actividad humana es un medio para entender la crisis ambiental. La actividad humana no se cuestiona en sí misma, sino sólo en sus resultados; resultados que por cristalizar en el ambiente externo son resultados técnicos.

Prestar atención a las relaciones técnicas como causa de los problemas ambientales tiene sus ventajas: identifica las causas inmediatas, se basa en relaciones de causa-efecto visibles, y permite distinguir y clasificar los problemas ambientales unos de otros.

Una forma simple de agrupar los problemas ambientales es partir de los procesos productivos huma-

nos entendidos en su dimensión técnica. Distinguiendo lo que ingresa de lo que egresa del ciclo productivo.

Los recursos naturales que ingresan al ciclo productivo pueden ser depredados por sobreexplotación, como en el caso de especies marinas, o de animales salvajes o de pájaros etc. También pueden ser depredados los recursos no renovables, como en el caso de los hidrocarburos o de cualquier mineral. También los espacios físicos pueden ser depredados, como comúnmente acontece sobre las costas donde se concentra la población humana. De manera que, bajo el término de depredación, podemos agrupar a todos aquellos recursos, tanto los que pueden ser desprendidos de su contexto e ingresan como materia prima a los ciclos productivos, como aquellos que forman parte del paisaje, y son extinguidos en cuanto a la función paisajística que venían cumpliendo. Claro está, en la medida en que su consumo productivo sea más rápido que el ritmo de reposición, de ahí el concepto de depredación.

Los recursos humanos que salen del ciclo productivo pueden ser contaminantes, cuando son acumulados en cantidad o en calidad en un ecosistema que no puede reciclarlos a la misma velocidad, como es el caso del dióxido de carbono en la atmósfera, o de algunos nutrientes en los cursos de agua. Además de los residuos, los propios productos pueden ser contaminantes del medio ambiente, porque desprenden partículas o elementos químicos nocivos para la salud, como es el caso de la mayoría de los plásticos. Y también los propios productos útiles, una vez que cumplen su ciclo de vida, se convierten en basura y contaminan. De manera que bajo el término contaminación podemos agrupar todos los problemas ambientales que se ubican a la salida, que egresan de los procesos productivos.

Tanto la depredación como la contaminación están directamente relacionadas con las tecnologías utilizadas. De la tecnología depende el tipo de recurso que ingresa al ciclo productivo y también el que sale del proceso productivo. Al reducir la problemática ambiental a relaciones técnicas, toda la discusión ambiental se transforma en analizar qué técnicas son menos o más contaminantes; o cuáles permiten revertir los procesos de degradación y contaminación. Colocar que existen límites físicos al desarrollo es otra manera de considerar los problemas ambientales como técnicos, ya que ese límite ayuda a pensar qué tecnologías son más aptas según la frontera temporal que el límite físico impone.

Pero la historia de la humanidad es la historia del cambio y búsqueda de nuevas fuentes energéticas, de nuevas materias primas, de nuevas formas de organizar la materia - algo que es infinito al igual que el conocimiento científico - lo cual contradice el argumento de que hay límites físicos al crecimiento.

Una lectura superficial de la historia ha llevado a validar la interpretación técnica de la cuestión ambiental. Se dice, por ejemplo, que los pueblos primitivos vivían en equilibrio con la naturaleza; lo cual es falso. Los pueblos primitivos, a pesar de sus tecnologías atrasadas, depredaban e inclusive extinguieron especies. En sentido opuesto, también se dice que los países de la ex Unión Soviética, que no eran capitalistas, tenían tecnología industrial, y por tanto eran tan contaminantes como los capitalistas con igual tecnología. Pero no se dice que la ex Unión Soviética heredó la tecnología capitalista.

Entonces, si el problema es técnico, también habría una solución técnica para la problemática ambiental: tecnologías verdes, limpias, energías renovables, tecnologías de geo-ingeniería para revertir el calentamiento global, y así por delante. Si los problemas ambientales han sido resultado de tecnologías erradas, otra tecnologías, ahora correctas, pueden, solucionar la crisis ambiental. 


\section{De cómo las relaciones sociales comandan a las relaciones técnicas}

Al reducir los problemas ambientales a problemas técnicos la discusión ambientalista hegemónica estableció las reglas del juego y dificultó el avance del movimiento ambientalista en la medida en que este último aceptaba dichas reglas de juego. El caso del calentamiento global es el más elocuente. Gran parte del movimiento ambientalista fue asimilado a la idea de que el principal problema ambiental mundial es el calentamiento global. Se centró la discusión en un hecho técnico: la cantidad de partículas por millón de $\mathrm{CO}_{2}$ y otros contaminantes en el aire. Así establecidas las reglas del juego no hay salida más que reducir las emisiones o limpiar el aire; en cualquier caso una solución técnica a un problema técnico previamente creado.

No se puede desconocer que los efectos sobre la naturaleza externa son diferentes según el tipo de tecnología; y por eso las tecnologías limpias o verdes contienen algo de verdad. El problema es que las tecnologías no son neutras. Las relaciones técnicas no pueden ser analizadas separadamente de las relaciones sociales. Son estas últimas las que comandan a las primeras. Cuando existen relaciones sociales que promueven la degradación del ambiente, las alternativas técnicas sólo pueden ser paliativas, cambiar el problema de un lugar o tema para otro. Y, las relaciones sociales capitalistas desarrollan tendencias que impactan el ambiente externo.

Las relaciones capitalistas, por ejemplo, presionan mediante la competencia para que los ciclos de producción sean cada vez más cortos, usando más materia prima y produciendo más residuos. Mientras aquellos productores que logran ciclos más cortos obtienen, de manera inmediata y automática, mayores ganancias, reducir la depredación y contaminación exige un proceso planeado, ni inmediato ni automático y generalmente a contracorriente de las tecnologías en uso, pensadas y probadas para determinados ritmos de producción en ecosistemas específicos.

Ni que decir de la causa histórica de desequilibrio ambiental que el surgimiento de la producción capitalista legó a las futuras generaciones: la división campo ciudad. Fue la revolución industrial la que concentró la población en las áreas urbanas y despobló el campo, y que, en los términos de Marx, estableció la ruptura del metabolismo social con la naturaleza externa. A partir de allí la acumulación de materia en los lugares de consumo se distanció en tiempo, espacio y ecosistemas, de sus originales lugares de extracción, impidiendo los procesos naturales de digestión y recicle de materiales. Aunque fue un proceso que comenzó con la misma revolución neolítica, fue la revolución industrial la que profundizó la brecha a tal extremo de constituirse en la fuente del todos los problemas ambientales subsiguientes.
También las relaciones capitalistas presionan generando productos nuevos, que en la mayoría de los casos no agregan ventajas significativas para la vida humana, ampliando el abanico de materias primas utilizadas y de residuos generados, como en el caso de los productos no biodegradables o de la creación de nuevos seres vivos (virus) con implicaciones desconocidas para el futuro, o de fuentes de energía como la nuclear que utiliza contaminantes radiactivos de duración temporal geológica. Aunque nuevos productos no necesariamente son más degradantes, al igual que en los ejemplos anteriores, primero se inventan e ingresan al mercado y luego se analiza, cuando se hace y como resultado de presiones sociales, sus potenciales impactos ambientales.

También las relaciones capitalistas generan permanentes desequilibrios entre la oferta y la demanda, creando abundancia y escasez de mercancías en tiempo y espacio; y orientan para que las materias primas se utilicen allí donde pueden rendir mayores ganancias, llevando a que cereales que antes eran alimento directo de la población se conviertan en materia prima de la industria energética. La crisis alimenticia, que tuvo su primer cenit en 2008 y luego en 2011 es un ejemplo elocuente del impacto de las relaciones sociales capitalistas sobre recursos naturales tan estratégicos como el alimento. El incremento de los precios distancia cada vez más el producto de las necesidades de amplios sectores de la población mundial, mostrando cómo el uso de amplias superficies de suelo del mundo depende de la valorización del capital. Con las tecnologías de la información y los procesos neoliberales de desregulación de los mercados financieros durante la década del noventa se abrió el mundo a la globalización financiera. Los capitales se movieron rápidamente hacia aquellos sectores que rendían mayor ganancia, saturando las empresas punto com a principios del siglo 21 y creando la crisis de dicho sector en el 2001. Entonces los capitales emigraron al sector inmobiliario, inflando los precios de la vivienda hasta que en 2007-2008 sobrevino la crisis de la vivienda, arrastrando inclusive a bancos a la quiebra. Entonces los capitales volvieron a emigrar a los alimentos, inflando el mercado de futuros (derivados), lo cual se sumó al cambio en el destino de varios productos, que de alimentos se convirtieron en materia prima de energéticos, y también se sumó al incremento del consumo en China y otros países. El resultado es que amplias extensiones del globo terráqueo son transformadas siguiendo la lógica de la acumulación de ganancias, lo que subordina cualquier tipo de relación técnica a sus intereses del capital. Al igual que la economía mundial se convierte en un gran casino, la transformación del medio ambiente pasa a ser resultado de esa ruleta financiera. 
No hay manera de considerar los impactos ambientales sólo por los efectos de la tecnología y separados de las relaciones sociales capitalistas.

Muchos, sin embargo, argumentan que la mayor demostración del carácter técnico de los problemas ambientales fue dada por la contaminación en los países de la ex Unión Soviética. También allí se depredaba y contaminaba, y eso porque al igual que en los países capitalistas la base industrial era la gran industria. Pero en esto hay dos elementos que no deben descuidarse. El primero es que dichos países heredaron una tecnología capitalista, que había sido construida sin consideraciones ambientales. Y la tecnología, aunque comandada por las relaciones sociales, es la causa práctica de las transformaciones ambientales. El segundo es que los ex-países socialistas a su exterior, a nivel del mercado mundial, competían en una economía capitalista, estando sujetos a todas las implicaciones anotadas.

Dentro de relaciones capitalistas es posible dar solución a problemas ambientales puntuales, tanto sectoriales como geográficos, pero no es posible reorientar la economía hacia un desarrollo armónico con la naturaleza externa. Y, lo que es más importante aún, no hay manera de que el desarrollo capitalista solucione los grandes problemas de desigualdad social y pobreza que intrínsecamente genera.

\section{Conclusiones}

A ya cuatro décadas de que la cuestión ambiental irrumpió en las agendas políticas en la mayoría de los países del mundo no ha habido avances significativos. A pesar que el concepto de desarrollo sustentable se ha afianzado en los discursos y las políticas, eso no significó más que un tibio esfuerzo por cuestionar las nuevas tecnologías en cuanto a su potencial contaminación. Mientras tanto, las verdaderas causas de la degradación ambiental hay que buscarlas en las propia dinámica de búsqueda de ganancia del capitalismo, que exacerbado por la crisis económica se manifiesta también en crisis ambiental, crisis de vivienda, energética etc.

En este artículo mostramos analíticamente cómo la discusión en torno al concepto de desarrollo sustentable subordinó el discurso a problemas técnicos, reduciendo por tanto la solución también a la esfera técnica y sin cuestionar las relaciones sociales de producción que las comandan.

\section{Referencias}

FOLADORI, G.; TOMMASINO, H. Controversias sobre sustentabilidad. Estudos do CEPE, Santa Cruz do Sul, RS, n. 12, p. 21-36, 2000a.
El concepto de desarrollo sustentable treinta años después. Desenvolvimento e Meio Ambiente, UFPR, Curitiba, PR, n.1, p. 41-56, 2000b.

El enfoque técnico y el enfoque social de la sustentabilidad. Revista Paranaense de Desenvolvimento, Curitiba, PR, n. 98, p. 67-76, 2000c.

\section{Nota}

1 Véase al respecto Foladori e Tommasino (2000a, 2000b, 2000c).

\section{Guillermo Foladori}

gfoladori@gmail.com

Doctor en Economia, Universid Nacional Autónoma de México

Profesor del Doctorado en Estudios del Desarrollo de la Universidad Autónoma de Zacateca (UAZ), México

Humberto Tommasino

htommasino@gmail.com

Doutor em Desenvolvimento e Meio Ambiente, Universidade Federal do Paraná

Pro-rector de Extensión de la Universidad de la República (Udelar), Uruguay

Universidad Autónoma de Zacateca (UAZ)

Unidad Académica en Estudios del Desarrollo

Jardín Juárez 147

Centro Histórico

C.P.: 98000

Zacatecas - México

\section{Universidad de la República (Udelar)}

Comisión Sectorial de Extensión y Actividades en el Medio (CSEAM)

Brandzen 1956 apto 201

C.P.: 11.200

Montevideo - Uruguay 